\title{
NIÑOS HOSPITALIZADOS CON NEUMONÍA POR INFLUENZA AH1N1/2009 PANDÉMICO EN UN HOSPITAL DE REFERENCIA DE PERÚ
}

\author{
Edwin Miranda-Choque ${ }^{1, a}$, Carlos Ramírez ${ }^{1, a}$, Jorge Candela-Herrera ${ }^{1, b}$, Javier Díaz ${ }^{1, b}$, \\ Ana Fernández ${ }^{1, b}$, Lenka Kolevic ${ }^{1, b}$, Eddy R. Segura ${ }^{2,3, c}$, Sonia Farfán-Ramos ${ }^{4, d}$
}

\begin{abstract}
RESUMEN
Objetivos. Determinar las características clínicas y demográficas de la neumonía por el virus de influenza AH1N1/2009 pandémico en un hospital de referencia de Perú. Materiales y métodos. Se realizó un estudio serie de casos en niños hospitalizados por neumonía por influenza AH1N1/2009 pandémico en un hospital de referencia. Revisamos las historias clínicas entre los meses de junio a septiembre 2009. Todos los casos tuvieron confirmación virológica. Resultados. Se encontró 74 casos de neumonía por el virus de Influenza AH1N1/2009 pandémico (NVIp), de los cuales 50 tuvieron el diagnóstico de neumonía adquirida en la comunidad viral (NACv) y 24 con neumonía nosocomial viral (NNv) de los cuales 16 requirieron ventilación mecánica. Fallecieron 12, todos ellos con antecedentes de comorbilidad. Los casos NNv presentaron asociación estadística con mortalidad. En los casos NACv, los menores de 6 años representaron $72 \%(36 / 50)$. La mediana de tiempo de enfermedad fue de 5 días. Los síntomas más frecuentes fueron fiebre, tos, rinorrea. Recibieron oseltamivir el $82 \%$. En la radiografía de tórax el $48 \%$ de los casos presentó infiltrado en parches y el $44 \%$ infiltrado intersticial en la radiografía de tórax. La proteína $\mathrm{C}$ reactiva (PCR) mayor a 10mg/L tuvo una asociación significativa con insuficiencia respiratoria $(p<0,05)$. Conclusiones. Encontramos casos NNv quienes tuvieron mayor mortalidad, también los que presentaron el PCR elevado y los que presentaron condición preexistente.
\end{abstract}

Palabras clave: Subtipo H1N1 del virus de la influenza A; Virus de la influenza; Neumonía; Niño (fuente: DeCS BIREME).

\section{CHILDREN HOSPITALIZED WITH INFLUENZA PNEUMONIA AH1N1/2009 PANDEMIC IN THE INSN}

\begin{abstract}
ObjectiveTo determine the clinical and demographic characteristics of pneumonia with influenza virus AH1N1/2009 pandemic at the National Institute of Child. Methods. Retrospective case series in children hospitalized for influenza pneumonia pandemic AH1N1/2009 in a pediatric hospital. Reviewed the medical records between the months of June to September 2009. All cases had virological confirmation, we describe the clinical characteristics and conditions of severity. Results. A total of 74 children of pneumonia with influenza virus AH1N1/2009 pandemic (NVIp), of those 50 were community acquire pneumonia viral (NACv) and 24 pneumonia nosocomial viral (NNv), 16 required mechanical ventilation. 12 died, all had preexisting factors. NN cases showed statistical association with mortality. The most frequent factors were malnutrition, respiratory infections, congenital heart disease and neurological deficits In NACv cases the children under 6 years accounted for $72 \%$ (36/50). The median disease duration was 5 days. The most frequent symptoms were fever, cough, runny nose. Received oseltamivir $82 \%$. The chest radiograph $48 \%$ of cases showed patchy infiltrates and $44 \%$ interstitial infiltrate on chest radiograph. Protein c reactive (CRP) more than $10 \mathrm{mg} / \mathrm{L}$ was significantly associated with respiratory failure $(p<0.05)$. Conclusions. Cases of NN found who had more mortality, even those who had the highest PCR and those with preexisting condition.
\end{abstract}

Key words: Influenza A Virus, H1N1 Subtype; Orthomyxoviridae; Pneumonia; Child (source: MeSH NLM).

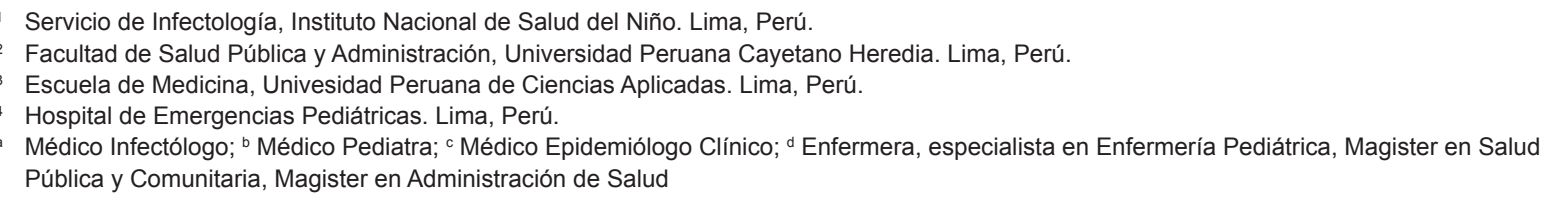

Médico Infectólogo; ${ }^{\mathrm{b}}$ Médico Pediatra; ' Médico Epidemiólogo Clínico; ${ }^{\mathrm{D}}$ Enfermera, especialista en Enfermería Pediátrica, Magister en Salud Pública y Comunitaria, Magister en Administración de Salud

Recibido: 03-06-11 Aprobado: 26-10-11 


\section{INTRODUCCIÓN}

La pandemia producida por virus de influenza AH1N1/2009 pandémico, declarado así por la Organización Mundial de la Salud (OMS) (1), fue ocasionada por este agente que presentó una nueva variante viral por recombinación genética con elementos porcinos, aviarios y humanos ${ }^{(2)}$. Este virus amenazaba con ocasionar un serio problema de salud pública con consecuencias sanitarias, sociales y económicas a nivel sudamericano ${ }^{(3)}$.

Los primeros casos ocurrieron a mediados de abril del 2009 al sur de EEUU y en Oxaca México (4-7), extendiéndose posteriormente a nivel mundial (8). Instituciones internacionales (OMS) y nacionales elaboraron medidas frente a la pandemia ${ }^{(9-12)}$, como el uso de oseltamivir a los casos confirmados o fuertemente sospechosos con presentación clínica severa o progresiva, y a los grupos de alto riesgo como niños menores de 5 años y adultos mayores.

La Dirección General de Epidemiologia (DGE) del Ministerio de Salud (MINSA) informó el primer caso en Lima, de un viajero proveniente de New York el 09 de mayo de $2009{ }^{(13)}$. El primer caso pediátrico reportado por el Instituto Nacional de Salud del Niño (INSN) fue el 17 de mayo de 2009, de un adolescente de 16 años, atendido por consultorio externo mientras que el primer caso hospitalizado fue el 27 de mayo, de un niño de 11 meses.

Estudios iniciales en niños hospitalizados por el virus de influenza AH1N1/2009 reportaron mayor tasa de hospitalizaciones que los casos hospitalizados por influenza estacional ${ }^{(14)}$. Los casos pueden ser desde asintomáticos u oligosintomáticos hasta llegar a casos severos como neumonías con insuficiencia respiratoria. Estas manifestaciones incluyen tos, alza térmica, cefalea, malestar general, artralgias, mialgias, rinorrea, dolor de garganta, disnea, roncantes, sibilantes crepitantes, síntomas gastrointestinales como diarrea o vómitos; cursando con complicaciones neurológicas (convulsiones y encefalitis), complicaciones hematológicas (pancitopenia) ${ }^{(15,16)}$ así como empeoramiento de enfermedades crónicas como asma y neumonía bacteriana ${ }^{(17)}$.

Se plantea que el espectro clínico de la infección por el virus de influenza AH1N1/2009 pandémica tiene relación con el reordenamiento genético inicial hasta su posterior estabilidad genética, además con la etnicidad y el estado inmunológico del huésped (17,18). El presente estudio tiene como objetivo determinar las características clínicas y demográficas de la neumonía asociada al virus de influenza AH1N1/2009 pandémica en el INSN.

\section{MATERIALES Y MÉTODOS}

\section{DISEÑO DE ESTUDIO}

Realizamos un estudio de serie de casos. Se identificó los casos hospitalizados con diagnóstico de neumonía registrados en la Oficina General de Epidemiologia del INSN entre los meses de junio y septiembre de 2009. Se incluyó a pacientes con diagnóstico viral confirmado por transcriptasa reversa de la reacción en cadena de polimerasa en tiempo real (tr-PCR-TR) realizado en el Instituto Nacional de Salud (INS) del Perú. Se excluyó aquellos que no presentaron sintomatología aguda, infiltrado pulmonar, así como cinco casos por tener historias clínicas incompletas.

Se definió como caso de neumonía por el virus de influenza AH1N1/2009 pandémico (NVIp) aquellos pacientes con síntomas respiratorios agudos como tos, disnea, dolor de garganta, con alza térmica mayor o igual de $38{ }^{\circ} \mathrm{C}$ o antecedente de fiebre; se clasificó como neumonía adquirida en la comunidad viral (NACv) si la trasmisión ocurrió en la comunidad y acudieron por consultorio o por emergencia y como neumonía nosocomial viral (NNv) si la enfermedad se desarrolló después de 72 horas del ingreso al hospital.

Se recolectó información a través de una ficha de datos elaborada por los autores. En los casos de NACV se registró variables al ingreso de la hospitalización como edad, sexo, tiempo de enfermedad, hipoxemia, estado nutricional, antecedente de asma o sindrome de obstrucción bronquial, contacto a sintomáticos respiratorios, comorbilidades. Asimismo, datos de exámenes auxiliares como hemograma completo, bioquímica sanguínea y radiografías de tórax. En los casos NNv la información se basó en la historia clínica, resultado de la activa vigilancia epidemiológica del INSN.

La causa de muerte se definió de la siguiente manera: A) Directa: atribuida principalmente al virus de influenza AH1N1/2009 pandémico. B) Relacionada: la causa principal de muerte es otra enfermedad diferente al de la influenza AH1N1/2009 pandémico; sin embargo, esta agravó el estado de salud. C) Coincidente: la causa de muerte es otra enfermedad diferente del virus de influenza AH1N1/2009 pandémico. La causa de muerte se determinó por junta médica, la cual estuvo conformada por dos médicos infectólogos pediatras, tres epidemiólogos, dos intensivistas pediatras, un genetista, un radiólogo y un neumólogo pediatra.

El estudio fue aprobado por la unidad de capacitación e investigación del INSN. 


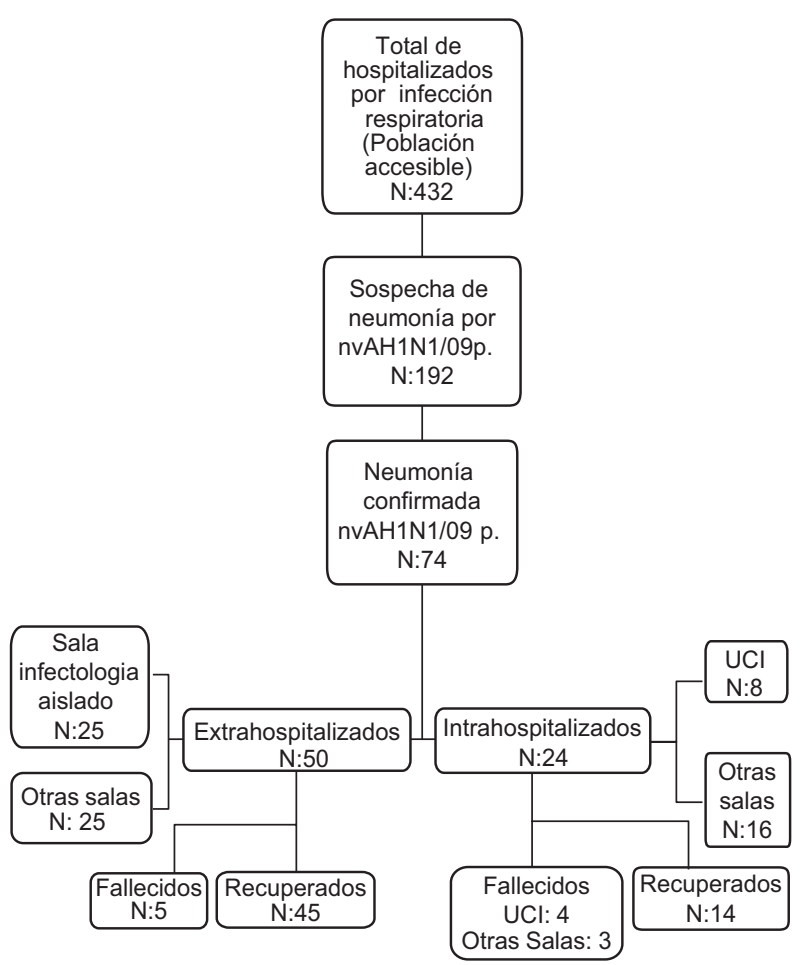

Figura 1. Flujograma de selección de participantes en el estudio.

\section{ANÁLISIS ESTADÍSTICO}

Por medio de software estadístico STATA versión 10 , se identificó la media, mediana y porcentajes. En el análisis bivariado se consideró insuficiencia respiratoria. Para las variables discretas se realizó el chi cuadrado, prueba exacta de Fisher. Se usó regresión logística mediante modelos anidados para identificar los factores que afectan el riesgo de muerte con las variables más representativas. Además se exploró,

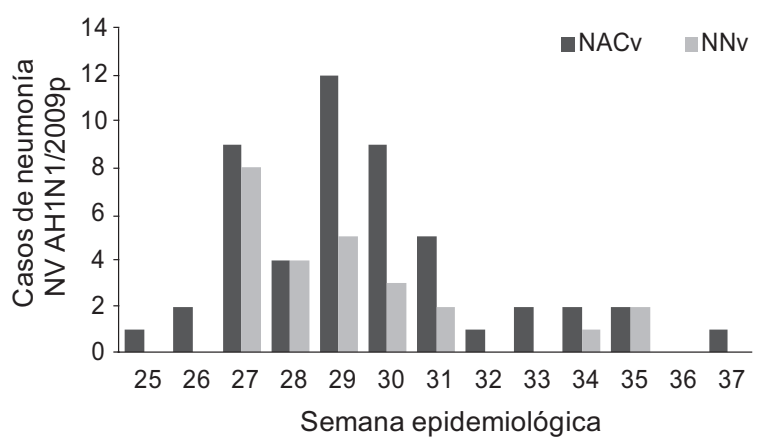

Figura 2. Número de hospitalizados con neumonía por el virus AH1N1/2009 pandémico según la semana de inicio de síntomas, INSN, Perú. Jun.-Set. 2009.

NACv: Neumonía adquirida en la comunidad viral. NNv: Neumonía nosocomial viral. solo en los casos NACv, asociación para insuficiencia respiratoria. Se consideró como diferencia significativa un valor de $p<0,05$.

\section{RESULTADOS}

Entre junio y septiembre de 2009 se hospitalizaron 432 pacientes con diagnóstico de infección respiratoria aguda. Se encontró 192 casos de neumonía, de los cuales 74 pacientes presentaron NVIp (50 casos NACV y 24 casos NNv) (Figura 1). La Figura 2 representa de la distribución de los casos NACv y NNv según semana epidemiológica.

\section{NEUMONÍA ADQUIRIDA EN LA COMUNIDAD POR EL VIRUS DE INFLUENZA AH1N1/2009 PANDÉMICO (NACV).}

El $64 \%(32 / 50)$ recibió antibióticos antes de la hospitalización. Requirieron de oxigeno 16 (32\%), requirieron ventilador mecánico $8(16 \%)$, recibieron oseltamivir 41 (82\%). La mediana de tiempo de enfermedad antes de llegar al hospital fue de 5 días (rango 1 a 10 días). El promedio de días de hospitalización fue de 10 días (rango de

Tabla 1. Características de los pacientes hospitalizados con neumonía por el virus de influenza AH1N1/2009 pandémico en el INSN, Lima-Perú, junio-septiembre 2009.

\begin{tabular}{|c|c|c|c|}
\hline CARACTERÍSTICAS & $\begin{array}{l}\text { NACv } \\
\text { N (\%) }\end{array}$ & $\begin{array}{r}\text { NNv } \\
\text { N (\%) }\end{array}$ & TOTAL \\
\hline Todos los casos & 50 & 24 & 74 \\
\hline Hombres (Sexo) & $24(48)$ & $14(58)$ & $38(51)$ \\
\hline \multicolumn{4}{|l|}{ Edad (años) } \\
\hline Mediana & 2 & 7 & 2,5 \\
\hline Rango & $0,1-15$ & $0,1-17$ & $0,1-17$ \\
\hline \multicolumn{4}{|l|}{ Grupo etario } \\
\hline$<2$ años & $24(48)$ & $5(21)$ & $29(39)$ \\
\hline 2-5 años & $12(24)$ & $3(13)$ & $15(20)$ \\
\hline 6-18 años & $14(28)$ & $16(67)$ & $30(41)$ \\
\hline \multicolumn{4}{|l|}{ Procedencia } \\
\hline Lima & $46(92)$ & $13(54)$ & $59(80)$ \\
\hline \multicolumn{4}{|l|}{ Comorbilidad } \\
\hline Ninguno & $11(22)$ & ----- & $11(15)$ \\
\hline Asma/SOBA & $16(32)$ & $2(8)$ & $18(24)$ \\
\hline Déficit neurológico crónico & $13(26)$ & $3(13)$ & $16(22)$ \\
\hline Desnutrición aguda & $8(16)$ & $5(21)$ & $13(18)$ \\
\hline Desnutrición crónica & $8(16)$ & $8(33)$ & $16(22)$ \\
\hline Infección respiratoria previa & $7(14)$ & $6(25)$ & $13(18)$ \\
\hline VIH & $2(4)$ & ---- & $2(3)$ \\
\hline Sd. Down/Klinefelter & $2(4)$ & $1(8)$ & $3(4)$ \\
\hline Cardiopatía congénita & $2(4)$ & $4(17)$ & $6(8)$ \\
\hline Pancitopenia/neutropenia & $1(2)$ & $3(13)$ & $4(5)$ \\
\hline
\end{tabular}


3 a 30 días). Al preguntarle a la responsable del cuidado del paciente, si existió otros integrantes de la familia con tos, el $64 \%$ (32/50) respondió afirmativamente, siendo 4 la mediana de número de integrantes de familia por caso.

En relación a exámenes auxiliares, el $48 \%$ presentó leucocitosis, $34 \%$ linfopenia, $14 \%$ presentó leucopenia y el $10 \%$ trombocitosis. Se encontró PCR mayor a $10 \mathrm{mg} / \mathrm{L}$ en 13 pacientes. Con respecto a la radiografía de tórax, el $48 \%(24 / 50)$ presentó infiltrado en parches y el $44 \%$ $(22 / 50)$ infiltrado intersticial. Las complicaciones que se encontraron fueron neumonía complicada con absceso o derrame pleural (cuatro casos), pancitopenia (dos casos), encefalitis viral (un caso) y otitis media aguda (un caso).

En el análisis de regresión logística se encontró que el PCR mayor a $10 \mathrm{mg} / \mathrm{L}$ estaba asociado con insuficiencia respiratoria hallándose un OR de 4,2 (IC:1,5-6,8, $p=0,001)$. Siendo la insuficiencia respiratoria cuatro veces más frecuentes con la PCR mayor de $10 \mathrm{mg} / \mathrm{L}$ en los niños con PCR menor. No se encontró asociación con el antecedente de asma o el uso de oseltamivir (Tabla 3).

\section{NEUMONÍA NOSOCOMIAL POR EL VIRUS DE INFLUENZA AH1N1/2009 PANDÉMICO (NNV)}

De los 24 casos de NNv, ocho casos se encontraban en la Unidad de Cuidados Intensivos y los 16 restantes se encontraron hospitalizados en salas de medicina, cardiología, neumología, nefrología y neurología.

Tabla 2. Signos y síntomas clínicos en niños hospitalizados con NACv, Lima-Perú, Junio-Setiembre 2009.

\begin{tabular}{lc}
\hline Signos y síntomas & Valores (\%) \\
\hline Fiebre & $45(90)$ \\
\hline Tos & $43(86)$ \\
\hline Rinorrea & $30(60)$ \\
\hline Subcrepitantes & $25(50)$ \\
\hline Sibilancias & $24(48)$ \\
\hline Roncates & $23(46)$ \\
\hline Expectoración & $22(44)$ \\
\hline Odinofagia & $17(34)$ \\
\hline Astenia & $17(34)$ \\
\hline Crepitantes & $16(32)$ \\
Vómitos & $14(28)$ \\
\hline Diarrea & $14(28)$ \\
\hline Mialgia & $5(10)$ \\
\hline Cefalea & $4(8)$ \\
\hline Dolor abdominal & $4(8)$ \\
\hline
\end{tabular}

Los mayores de 6 años representa la mayoría de los casos con el $67 \%$ (16/24). Las comorbilidades más frecuentes fueron desnutrición crónica e infecciones respiratorias previas, cardiopatía congénita y déficit neurológico crónico. Ocho casos estuvieron en ventilador mecánico. Los casos fallecidos fueron siete (mortalidad de $29 \%$ ) y presentaron como antecedente pancitopenia (2), cardiopatía congénita (3) lupus eritematoso sistémico (LES) (1) y dermatomiositis (1).

\section{FALLECIDOS EN LOS CASOS DE NEUMONÍA POR EL VIRUS DE INFLUENZA AH1N1/2009 PANDÉMICO.}

Con respecto a los doce casos fallecidos, cinco fueron NACv y 7 fueron NNv (Tabla 4). Mediante el análisis de regresión logística se encontró que ser un caso NNv es riesgo de fallecer por Neumonía asociado al virus de influenza AH1N1/2009 pandémico con un OR de 4,7 (IC: 1,1-20,1, p=0,02) (Tabla 3). No se encontró asociación entre el uso de oseltamivir, antecedente de asma/soba o los valores de PCR.

\section{DISCUSIÓN}

El impacto de la pandemia del virus de influenza AH1N1/2009 pandémico en el INSN, se ha traducido en un incremento del número de casos entre la semana 28 a la semana 35 , con mayor actividad en la semana 29 ,

Tabla 3. Resultados de análisis de regresión logística de indicadores pronóstico de severidad, niños hospitalizados con neumonía por el virus de influenza AH1N1/09 pandémico, Lima-Perú, junio - septiembre 2009.

\begin{tabular}{lcc}
\hline & \multicolumn{1}{l}{$\begin{array}{l}\text { Odds ratio } \\
\text { (IC 95 \%) }\end{array}$} & $\boldsymbol{p}$ \\
\hline Total de casos * & $4,7(1,1-20,1)$ & 0,032 \\
\hline Ser caso NNv & $1,7(0,4-7,2)$ & 0,428 \\
Desnutrición & $3,5(0,7-16,3)$ & 0,105 \\
PCR $\geq 10 \mathrm{mg} / \mathrm{L}$ & $0,1(0,1-1,0)$ & 0,721 \\
\hline Antecedente asma & $0,8(0,2-3,4)$ & 0,054 \\
Uso de oseltamivir & & \\
Solo casos ambulatorios ** & $4,2(1,5-6,8)$ & 0,002 \\
PCR $\geq 10 \mathrm{mg} / \mathrm{L}$ & $2,2(0,6-8,2)$ & 0,245 \\
Antecedente de SOBA/ & $1,6(1,0-4,3)$ & 0,444 \\
Asma & $2,4(0,3-17,1)$ & 0,361 \\
\hline Tiempo enfermedad $\leq 2$ días
\end{tabular}

* Análisis de regresión logística, se consideraron todos los casos: NACV y NNv.

** Análisis de regresión logística de casos NACv. NACv: Neumonía adquirida en la comunidad viral. NNv: Neumonía nosocomial viral. 
datos que coinciden con estudios de vigilancia nacional en el Perú ${ }^{(13)}$. Es importante señalar que el $32 \%$ (24/74) de los casos confirmados son niños con el antecedente de hospitalización previa, lo cual los hace más susceptibles de infección como lo sugieren otros estudios ${ }^{(19,20)}$.

La información brindada de la vigilancia nacional de los casos de influenza por el virus AH1N1/2009 pandémico en niños por grupos etarios, indica que a medida que se incrementa la edad se incrementan el número de casos ${ }^{(13)}$, a diferencia de los niños que requirieron hospitalización (como en nuestro estudio) el comportamiento es inverso, los casos de NACv son más frecuentes en los menores de 2 años y después desciende la frecuencia a medida que aumenta la edad, información parecida a otros estudios (21-24). Sin embargo en los casos NNv los mayores de 6 años son más frecuentes.

Se evidenció que los casos NACv en el momento de su ingreso por emergencia, la presencia de hipoxemia en el $32 \%$ (16/50), siendo este porcentaje variable en otros estudios (21-23). Información importante para la implementación de medidas en la atención en los diferentes niveles de atención.

En nuestro estudio la variable uso del antiviral oseltamivir, es un dato no precisado, al no conocerse el tiempo exacto del inicio de ingesta del medicamento; sin embargo, sería interesante analizar la relación con estudios más amplio; últimos reportes no demuestran el efecto deseado en la eliminación del virus ${ }^{(25)}$.

En los casos NACv los síntomas gastrointestinales como diarrea o vómitos, mencionados como importantes en la presentación clínica según la guía de la OMS y directiva sanitaria del MINSA, es adecuada si consideramos que lo presentaron el $28 \%(14 / 50)$ de los casos de NACv y tres de los cinco que llegaron a morir; sin embargo, no fue posible demostrar la asociación significativa, probablemente porque la muestra es insuficiente.

Determinar el tipo de muerte por el virus de influenza AH1N1/2009 pandémico fue controversial. Los fallecidos con numerales 1,5 y 8 (Tabla 4) se consideraron coincidentes por presentar signos y síntomas de infección respiratoria mínima, pero los dos primeros casos fallecieron por falla hepática con complicaciones metabólicas y por infarto cardiaco en el tercero.

De los informes de Microbiología de los hemocultivos que se tomaron a todos los casos ambulatorios previo uso de antibióticos en emergencia, se aisló solamente un caso con Estreptococo pneumoniae. Esto confirmaría la coinfección de una bacteria y el virus de

Tabla 4. Pacientes fallecidos con neumonía por el virus de influenza AH1N1/2009 pandémico en el INSN, Lima-Perú, junio - septiembre 2009.

\begin{tabular}{|c|c|c|c|c|c|c|c|}
\hline N. ${ }^{\circ}$ & Edad & Sexo & Condición preexistente & $\begin{array}{c}\text { Días } \\
\text { hospital }\end{array}$ & Trasmisión & Diagnóstico & $\begin{array}{l}\text { Causa de } \\
\text { muerte* }^{*}\end{array}$ \\
\hline 1 & 11 años & M & Pancitopenia, falla hepática & 11 & Nosocomial & $\begin{array}{c}\text { Falla } \\
\text { multiorgánica }\end{array}$ & Coincidente \\
\hline 2 & 2 años & M & Hidrocefalia, reflujo gástrico & 9 & Ambulatorio & Neumonía viral & Directa \\
\hline 3 & 4 años & $\mathrm{F}$ & Mielomeningocele, $\mathrm{PCl}^{\star * *}$ & 13 & Ambulatorio & Neumonía viral & Directa \\
\hline 4 & 7 meses & $\mathrm{F}$ & Microcefalia, agenesia cuerpo calloso & 10 & Ambulatorio & Neumonía viral & Directa \\
\hline 5 & 10 años & M & Pancitopenia, falla Hepática & 5 & Nosocomial & $\begin{array}{c}\text { Falla } \\
\text { multiorgánica }\end{array}$ & Coincidente \\
\hline 6 & 2 meses & $\mathrm{F}$ & Cardiopatía congénita, NAV** & 26 & Nosocomial & $\begin{array}{c}\text { Falla } \\
\text { multiorgánica }\end{array}$ & Relacionada \\
\hline 7 & 5 meses & $\mathrm{F}$ & $\begin{array}{l}\text { Cardiopatía congénita, displasia } \\
\text { Broncopulmonar }\end{array}$ & 7 & Nosocomial & $\begin{array}{c}\text { Falla } \\
\text { multiorgánica }\end{array}$ & Relacionada \\
\hline 8 & 13 años & $\mathrm{F}$ & Cardiopatía congénita & 19 & Nosocomial & $\begin{array}{l}\text { Infarto de } \\
\text { miocardio }\end{array}$ & Coincidente \\
\hline 9 & 14 años & $\mathrm{F}$ & Lupus eritematoso sistémico & 10 & Nosocomial & Neumonía viral & Directa \\
\hline 10 & 14 años & $M$ & Dermatomiositis & 14 & Nosocomial & $\begin{array}{c}\text { Falla } \\
\text { multiorgánica }\end{array}$ & Directa \\
\hline 11 & 2 años & M & Síndrome klinefelter & 11 & Ambulatorio & Neumonía viral & Directa \\
\hline 12 & 2 años & M & $\begin{array}{l}\text { Síndrome de down, cardiopatía } \\
\text { congénita }\end{array}$ & 24 & Ambulatorio & $N A V^{* *}$ & Relacionada \\
\hline
\end{tabular}

* Causa de muerte: A) Directa: atribuida principalmente al virus de influenza AH1N1/2009 pandémico. B) Relacionada: la causa principal de muerte es otra enfermedad diferente al de la influenza AH1N1/2009 pandémico; sin embargo, esta agravó el estado de salud. C) Coincidente: la causa de muerte es otra enfermedad diferente del virus de influenza AH1N1/2009 pandémico.

** NAV: neumonía asociada a ventilador.

${ }^{* * *} \mathrm{PCl}$ : parálisis cerebral Infantil. 
la influenza AH1N1/09 pandémica en el desarrollo de neumonía ${ }^{(26) .}$

No se tiene datos de coinfección de la NIVp con otros virus en el INSN, considerando que en vigilancia en otras instituciones evidencian la circulación de otros virus ${ }^{(27)}$, siendo este dato importante para la detección oportuna de brotes, vigilancia de la circulación de virus respiratorios y severidad de los casos, por lo que sugerimos considerar al INSN centro de vigilancia nacional de infecciones respiratorias.

Estos datos pueden ayudar en la atención ante otra eventual situación de brote de infección viral respiratoria. Se sugiere considerar la vacunación a los hospitalizados en pediatría por tener un riesgo elevado de fallecer. Creemos que si existe un brote de infección respiratoria viral en la comunidad, esta sería mayor a nivel hospitalario en servicios que atienden niños por ser trasmitida entre pacientes, familiar acompañante y personal de salud, por lo que sugerimos reforzar las medidas de prevención y control de infecciones nosocomiales, como la higienización de las manos (lavado de manos y uso de alcohol gel), y tomar precauciones de aislamientos.

En conclusión, la mayoría de los casos de niños con neumonía por el virus de influenza AH1N1/2009 pandémico se presentaron entre junio y septiembre de 2009. El $32 \%$ de los casos fueron NNv. El grupo etario más numeroso en los casos NACv son los menores de seis años y en los casos NNv son los mayores de cinco años. Recibieron oseltamivir el $82 \%$ de los pacientes. El $48 \%$ de los casos presentó infiltrado en parches y el $44 \%$ infiltrado intersticial en la radiografía de tórax. Los fallecidos fueron más en los casos NNv. El incremento de los valores del PCR se asoció a los casos de insuficiencia respiratoria. La principal limitación de la presente investigación fue utilizar fuentes secundarias para el recojo de información.

\section{AGRADECIMIENTOS}

A la Dra. Trinidad Del Pino Greco por la lectura de las radiografías de Tórax, a los residentes de pediatría, internos, enfermeras, personal técnico del Servicio de Infectología del INSN.

\section{Contribuciones de autoría}

EM-CH participó en la concepción y diseño del trabajo, análisis e interpretación de datos, redacción de la primera versión del manuscrito, redacción de la versión final del manuscrito, CR participó en el análisis e interpretación de datos y redacción de la primera versión del manuscrito, JC-H participó en la concepción y diseño del trabajo, interpretación de datos, y redacción de la primera versión del manuscrito, JD participó en la concepción y diseño del trabajo, interpretación de datos, y redacción de la primera versión del manuscrito, AF participó en la concepción y diseño del trabajo, LK participó en la concepción y diseño del trabajo, ES participó en el diseño del trabajo, análisis, interpretación de datos y redacción del manuscrito, SF-R participó en el diseño, análisis, interpretación de datos y redacción del manuscrito. Todos los autores revisaron en forma crítica versiones preliminares del manuscrito y aprobaron la versión final del trabajo.

\section{Fuentes de financiamiento}

Este trabajo ha sido financiado por la unidad de capacitación del Instituto Nacional de Salud del Niño (INSN).

\section{Conflictos de interés}

Los autores declaran no tener conflictos de interés en la publicación de este artículo.

\section{Descargo de Responsabilidad}

Las opiniones y afirmaciones contenidas aquí son propias de los autores y no deben interpretarse como posición oficial o que reflejan la opinión del INSN.

\section{REFERENCIAS BIBLIOGRÁFICAS}

1. Chan M. World now at start of 2009 influenza pandemic. Geneva: WHO; 2009.

2. Dawood FS, Jain S, Finelli L, Shaw MW, Lindstrom $\mathbf{S}$, Garten RJ, et al. Emergence of a novel swine-origin influenza A (H1N1) virus in humans. N Engl J Med. 2009;360(25):2605-15

3. Laguna-Torres VA, Benavides JG. Infection and death from influenza A H1N1 virus in Mexico. Lancet. 2009;374(9707):2032-3.

4. Childs RA, Palma AS, Wharton S, Matrosovich T, Liu Y, Chai W, et al. Receptor-binding specificity of pandemic influenza A (H1N1) 2009 virus determined by carbohydrate microarray. Nat Biotechnol. 2009;27(9):797-9.

5. Bermejo-Martin JF, Kelvin DJ, Eiros JM, Castrodeza J, Ortiz de Lejarazu R. Macrolides for the treatment of severe respiratory illness caused by novel H1N1 swine influenza viral strains. J Infect Dev Ctries. 2009;3(3):159-61.

6. Sherman SE, Foster J, Vaid S. Emergency Use Authority and 2009 H1N1 influenza. Biosecur Bioterror. 2009;7(3):245-50.

7. Centers for Disease Control and Prevention (CDC). Update: novel influenza A (H1N1) virus infection - Mexico, March-May, 2009. MMWR Morb Mortal Wkly Rep. 2009;58(21):585-9.

8. Scalera NM, Mossad SB. The first pandemic of the $21 \mathrm{st}$ century: a review of the 2009 pandemic variant influenza A (H1N1) virus. Postgrad Med. 2009;121(5):43-7. 
9. World Health Organization. Pandemic influenza preparedness and response. A WHO guidance document. Geneva: WHO; 2009.

10. World Health Organization. WHO Global Influenza Preparedness Plan 2005. Annex 1: Recommendations for non-pharmaceutical public health measures. Geneva: WHO; 2005.

11. Ministerio de Salu del Perú. Plan Nacional de Preparación y Respuesta ante Potencial Pandemia de Influenza. Lima: MINSA; 2005

12. Mayo Hd. Guia practica clinica para el diagnostico y tratamiento de Infuenza por el virus A H1N1. Guia Tecnica. Lima: MINSA; 2009.

13. Munayco CV, Gomez J, Laguna-Torres VA, Arrasco $\mathbf{J}$, Kochel TJ, Fiestas V, et al. Epidemiological and transmissibility analysis of influenza $A(\mathrm{H} 1 \mathrm{~N} 1) v$ in a southern hemisphere setting: Peru. Euro Surveill. 2009;14(32).

14. Libster R, Bugna J, Coviello S, Hijano DR, Dunaiewsky M, Reynoso N, et al. Pediatric hospitalizations associated with 2009 pandemic influenza A (H1N1) in Argentina. N Engl J Med. 2010;362(1):45-55.

15. Centers for Disease Control and Prevention (CDC). Neurologic complications associated with novel influenza A (H1N1) virus infection in children - Dallas, Texas, May 2009. MMWR Morb Mortal Wkly Rep. 2009;58(28):773-8.

16. O'Riordan S, Barton M, Yau Y, Read SE, Allen U, Tran D. Risk factors and outcomes among children admitted to hospital with pandemic $\mathrm{H} 1 \mathrm{~N} 1$ influenza. CMAJ. 2010;182(1):39-44

17. Zarychanski R, Stuart TL, Kumar A, Doucette S, Elliott L, Kettner J, et al. Correlates of severe disease in patients with 2009 pandemic influenza (H1N1) virus infection. CMAJ. 2010;182(3):257-64.

18. Yu H, Zhang GH, Hua RH, Zhang Q, Liu TQ, Liao M, et al. Isolation and genetic analysis of human origin H1N1 and H3N2 influenza viruses from pigs in China. Biochem Biophys Res Commun. 2007;356(1):91-6.

19. Perez-Padilla R, de la Rosa-Zamboni $D$, Ponce de Leon S, Hernandez M, Quinones-Falconi F, Bautista $\mathbf{E}$, et al. Pneumonia and respiratory failure from swineorigin influenza A (H1N1) in Mexico. N Engl J Med. 2009;361(7):680-9.
20. Wicker S, Rabenau HF, Bickel M, Wolf T, Brodt R, Brandt C, et al. [Novel influenza H1N1/2009: virus transmission among health care worker]. Dtsch Med Wochenschr. 2009;134(48):2443-6.

21. Lister P, Reynolds F, Parslow R, Chan A, Cooper M, Plunkett $\mathbf{A}$, et al. Swine-origin influenza virus H1N1, seasonal influenza virus, and critical illness in children. Lancet. 2009;374(9690):605-7.

22. Fraser C, Donnelly CA, Cauchemez S, Hanage WP, Van Kerkhove MD, Hollingsworth TD, et al. Pandemic potential of a strain of influenza A (H1N1): early findings. Science. 2009;324(5934):1557-61.

23. Louie JK, Acosta M, Winter K, Jean C, Gavali S, Schechter $\mathbf{R}$, et al. Factors associated with death or hospitalization due to pandemic 2009 influenza $A(\mathrm{H} 1 \mathrm{~N} 1)$ infection in California. JAMA. 2009;302(17):1896-902.

24. Muhammad Ismail HI, Tan KK, Lee YL, Pau WS, Razali KA, Mohamed T, et al. Characteristics of children hospitalized for pandemic (H1N1) 2009, Malaysia. Emerg Infect Dis. 2011;17(4):708-10.

25. Ling LM, Chow AL, Lye DC, Tan AS, Krishnan P, Cui L, et al. Effects of early oseltamivir therapy on viral shedding in 2009 pandemic influenza A (H1N1) virus infection. Clin Infect Dis. 2010;50(7):963-9.

26. Centers for Disease Control and Prevention (CDC). Bacterial coinfections in lung tissue specimens from fatal cases of 2009 pandemic influenza A (H1N1) - United States, May-August 2009. MMWR Morb Mortal Wkly Rep. 2009;58(38):1071-4.

27. Laguna-Torres VA, Gomez J, Aguilar PV, Ampuero JS, Munayco C, Ocana V, et al. Changes in the viral distribution pattern after the appearance of the novel influenza A H1N1 ( $\mathrm{pH} 1 \mathrm{~N} 1)$ virus in influenza-like illness patients in Peru. PLoS One. 2010;5(7):e11719.

Correspondencia: Edwin Miranda Choque Dirección: Av. Pachacutec 910, Lima 11, Perú. Teléfono: (511) 994645290

Correo electrónico: emirandach@hotmail.com

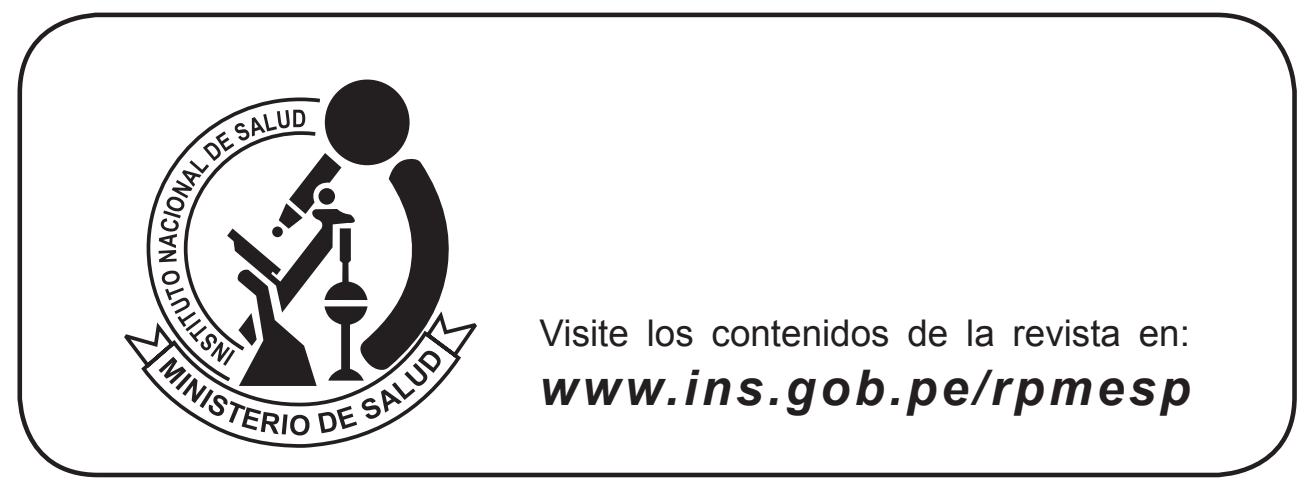

